\title{
A Study of Vertical Wind Turbine for Application in Low Wind Speed Condition in UiTM Terengganu, Malaysia
}

\author{
Ermeey Abd Kadir, Mohd Taib Miskon, Nasran Abd Rashid, Mat Yushafizee Yunus
}

Faculty of Electrical Engineering, Universiti Teknologi MARA, Terengganu Branch, Dungun, Malaysia

Email: eabd949@aucklanduni.ac.nz

How to cite this paper: Kadir, E.A., Miskon, M.T., Rashid, N.A. and Yunus, M.Y. (2018) A Study of Vertical Wind Turbine for Application in Low Wind Speed Condition in UiTM Terengganu, Malaysia. Journal of Power and Energy Engineering, 6, 38-48.

https://doi.org/10.4236/jpee.2018.68002

Received: May 17, 2018

Accepted: August 14, 2018

Published: August 17, 2018

Copyright (c) 2018 by authors and Scientific Research Publishing Inc. This work is licensed under the Creative Commons Attribution International License (CC BY 4.0).

http://creativecommons.org/licenses/by/4.0/

(c) (i) Open Access

\begin{abstract}
This paper presented an investigation of an energy generation project by using a wind turbine in UiTM Terengganu, Malaysia. The significance of the project is to evaluate the proposed wind energy setup with the tropical environmental condition, especially in Malaysia. The wind turbine is built close to the seashore and facing the South China Sea. A relationship between wind speed with and the voltage level at the energy generator output terminal is analysed theoretically. Published wind speed data has been used in determining a suitable wind turbine system. Actual wind speed data is recorded starting from June 2017 until December 2017, and the data is compared with the published results. It has been found that the recorded data is in line with the published results. Moreover, it has been found that the mean wind speed collected at the proposed site is low, which is $2 \mathrm{~m} / \mathrm{s}$ to $3.7 \mathrm{~m} / \mathrm{s}$. Furthermore, the wind turbine is actively producing energy for approximately 4 hours per day. A $300 \mathrm{~W}$ vertical axis wind turbine has been developed and tested, and it has been found that the efficiency of the energy generating system is less than $10 \%$, which contributes for a significant amount per month.
\end{abstract}

\section{Keywords}

Renewable Energy, Wind Energy Potential

\section{Introduction}

Energy from wind has been proved to be a reliable source for generating energy. A wind turbine is an energy generator use in converting the wind kinetic to electrical power [1]. Throughout Malaysia, especially in Terengganu, there are a few wind turbines been built to serve the energy requirement of a selected residence, 
especially in remote places [2]. However, most of the turbine does not operate as expected.

Currently, when designing a wind turbine, wind data from the local meteorological department is referred. However, most of the data collected only considered a very limited area of the location of the wind sensor station [3]. For a new proposed wind turbine location situated kilometers away from the wind gauge station, the assumption of the actual data contributes to measurement error [4]. Because the insufficient actual study at the chosen site may cause the wind turbine system selected not to work as expected. In a tropical country, the average wind speed recorded is in between 2 to $4 \mathrm{~m} / \mathrm{s}$ [5]. This low level of wind speed plays a major role in designing a suitable wind turbine which can generate the required energy. The current 3 -blade horizontal wind turbine required more than $4 \mathrm{~m} / \mathrm{s}$ for the blade start to spin and generating energy. The will be an issue if this type of wind turbine is in use, especially in Malaysia. From the previous wind turbine site, such as at Kuala Terengganu, it has been found that the average wind speed is low [1]. The wind speed strength is the main factor why a wind turbine has not been used widely as an alternative technique for generating electrical power in Malaysia [6] [7].

Before an investment is made to build up a wind turbine which can generate electric power, it is a best practice to plan an actual study at the proposed location where the wind turbine will be constructed [8]. A pilot study is necessary because all the unknown parameter such as local wind speed and energy generator active time can be measured. Both parameters will demonstrate the type of wind turbine generator which gives the best efficiency at the proposed site and how long the generator is active in a day and at the same time produces energy. Furthermore, a suitable wind turbine system can be easily selected that can operate efficiently at the chosen location environment.

In this research, a pilot study on a small-scale wind turbine which can generate electric power in low wind speed will be investigated. The study will start with an analytical calculation to find the relation between wind speed and the expected generator output voltage and power. Then, actual results on the wind speed at the proposed site will be recorded and compared with published data obtained from previous research. Finally, a Savonius type of vertical axis wind turbine (VAWT) will be designed and fabricated, and the system performances will be tested and reported which is summarized in the last section.

\section{Theory}

In designing a wind turbine system, a general equation can estimate the output voltage of the generator output terminal. The wind speed reflects the level of voltage. The relation between wind speed $w_{s}$ and the voltage level of the energy generator terminal $v_{c}$ can be represented as

$$
w_{s} \propto v_{a c}
$$

Equation (1) can be simplified, and the equation can be written as 


$$
w_{s}=k \cdot v_{a c}
$$

where $k$ is a constant value represent the unexplained losses occurred in the system which consumes the energy harvested from the wind. The relationship between parameter in Equation (2) can be illustrated by Figure 1.

Figure 1 illustrated as the wind speed moved to a higher value the voltage level at the energy generator output also increased. The increasing rate is directly related to the value of $k$. However, at a point, even the value of wind speed is high, and the constant $k$ is increasing the voltage level at the output terminal is fixed at a maximum value. As for energy storage purposes, the instantaneous signal at the generator output terminal will be converted to direct current signal which can be represented as

$$
v_{d}=2 v_{c}-v_{d r o p}
$$

where $\mathrm{v}_{\mathrm{d}}$ is the direct current voltage, and $v_{\text {drop }}$ is the voltage drop due to rectification circuit when converting the instantaneous signal for storage purpose. From Equation (3), the direct current voltage is half of the $v_{c}$.

The generated power from the energy generator is written as

$$
P_{\text {out }}=v_{d}^{2} / R
$$

where $P_{\text {out }}(\mathrm{W})$ is the output power of the wind turbine for a load of $R(\Omega)$. Figure 2, depicted the relationship between the parameters in Equation (4).

As illustrated in Figure 2, the amount of output power is increasing as the wind speed start to increase. However, the output power is sharply decreased as the output resistance moved to a higher value. From the figure, it is a requirement for the load to be small to produce a high output power from the energy generator.

The highlighted formula could also be applied in predicting generated energy for mini-hydro and small biomass energy generator. Both generators have the

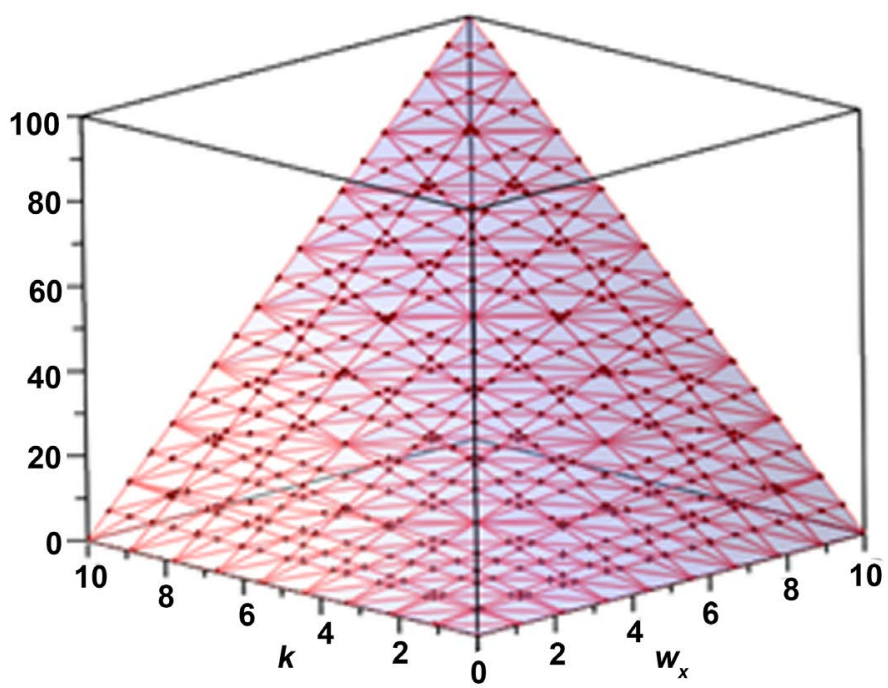

Figure 1. The relationship between wind speed $w_{s}$ and energy generator output voltage $v_{c}$ for variation of $k$. 


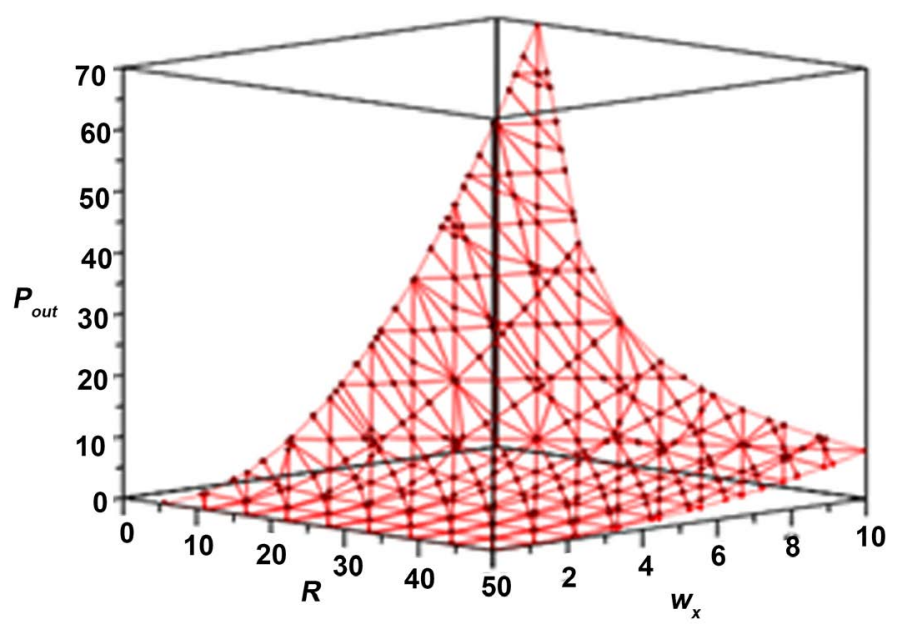

Figure 2. The relation of output power, load resistance and wind speed; $\mathrm{k}=1$.

same concept of generating energy which is using the pressure of water and steam, respectively, to rotates generating plates and produce energy.

\section{Methodology}

The approach taken in this section is to highlight the step in proposing a small wind turbine generator in UiTM Terengganu. Furthermore, the proposed step could be used as a reference document when a small-scale wind turbine generator to be set up at a similar site condition. The main purpose of setting up the energy generator in UiTM Terengganu is to look on an alternative approach that can reduce the campus spending on the electricity bill. The targeted saving is 5\% off the average monthly electricity bill.

The location of the wind turbine generator will be at Dungun Campus. The site is quite close to the sea bank which is approximately less than 1 kilometre. The common approach taken when a wind turbine generator will be set up is to found out what is the wind speed value for this proposed site. Previously, the best guest in designing such energy generator is to refer to the wind speed data from the nearest weather station. However, the closest weather station from the proposed site is more than 20 kilometres away. Figure 1 illustrated the mean wind speed measured from four different weather stations located along the east coast of Peninsular Malaysia. As shown in the figure, the wind speed along the region is between $1.2 \mathrm{~ms}$ to $4.4 \mathrm{~ms}$. For each station, the maximum recorded wind speed is in between November until January which is concurrent to the Northeast monsoon season that happens every year in the region.

From the figure also, the highest recorded wind speed is at the Mersing station. The main reason is due to the station position which is close to the South China Sea. The rest of the other stations is at a distance from the open sea which contributes to lesser wind speed than Mersing. The figure also demonstrates that if a traditional 3-Blade horizontal wind turbine generator is used in generating the electrical energy, the system could not work efficiently. 
The wind speed data reported in Figure 1 will be utilised as the reference in designing an efficient energy generator in UiTM Terengganu. However, to gain further clarification on the wind speed data, an actual investigation is required at the proposed site. The wind speed data need to be recorded, and a comparison is made with the reported wind speed data. At the proposed location, one Anemometer is installed at the height of 7 meters from the ground. A small wireless data recording system is set up to record the actual wind speed for 24 hours. The wireless data logging system arrangement is highlighted in Figure 2.

As shown in the figure, the Anemometer reacted to the wind speed which blows around it. The higher the wind speed is, the Anemometer will rotate accordingly. The Anemometer will start to rotate for a wind speed as low as $1 \mathrm{~m} / \mathrm{s}$. An output signal which is in term of DC voltage level will be sent to the Arduino transmitter (Tx) module. The Tx module will convert the signal into a pulse code modulation and transmit the data to the receiver $(\mathrm{Rx})$ module which is situated $500 \mathrm{~m}$ from the Tx module position. At the receiver side, the measured wind speed data will be stored in a hard disk at a personal computer for the following analysis.

Figure 3 illustrates one of the wind speed data recorded at the proposed site in UiTM Terengganu. As shown in the illustration the measured data is taken approximately for 48 hours. It has been found that in one day the anemometer only active close to 4 hours. The average wind speed for the time periods is approximately $3.8 \mathrm{~m} / \mathrm{s}$. Using the first parameter which is the wind speed sensor active time, the energy can be generated from a wind turbine can be calculated. Furthermore, and the average wind speed obtained at the proposed site, can be used to select the suitable wind turbine generator that could give the highest efficiency in generating energy at the proposed location.

\section{Vertical Axis Wind Turbine Generator System}

A vertical axis wind turbine generator is used for an actual experimentation. The experimentation will find out whether the idea of generating energy through wind turbine generator is a feasible approach in decreasing the electricity bill for the campus. The vertical axis wind turbine generating capacity is at $300 \mathrm{~W}$, and the actual figure of the turbine is depicted in Figure 4.

Figure 5 depicted a schematic of the vertical axis wind turbine generator and the system used in converting the harvested alternating energy to direct current power before being stored in the storage batteries. In the figure, the height of the wind turbine is $4.2 \mathrm{~m}$ from the ground surface. At the top of the generator is an anemometer where the wind speed is monitored and recorded. At the system container, all the required circuitry for the wind turbine generator is placed and sealed. The output of the wind turbine generator is two different signals which are $12 \mathrm{Vdc}$ and $240 \mathrm{Vac}$.

The vertical axis wind turbine generator system was set up in June 2015. Steelcon Energy Sdn Bhd fabricates the system, and the commission of the 


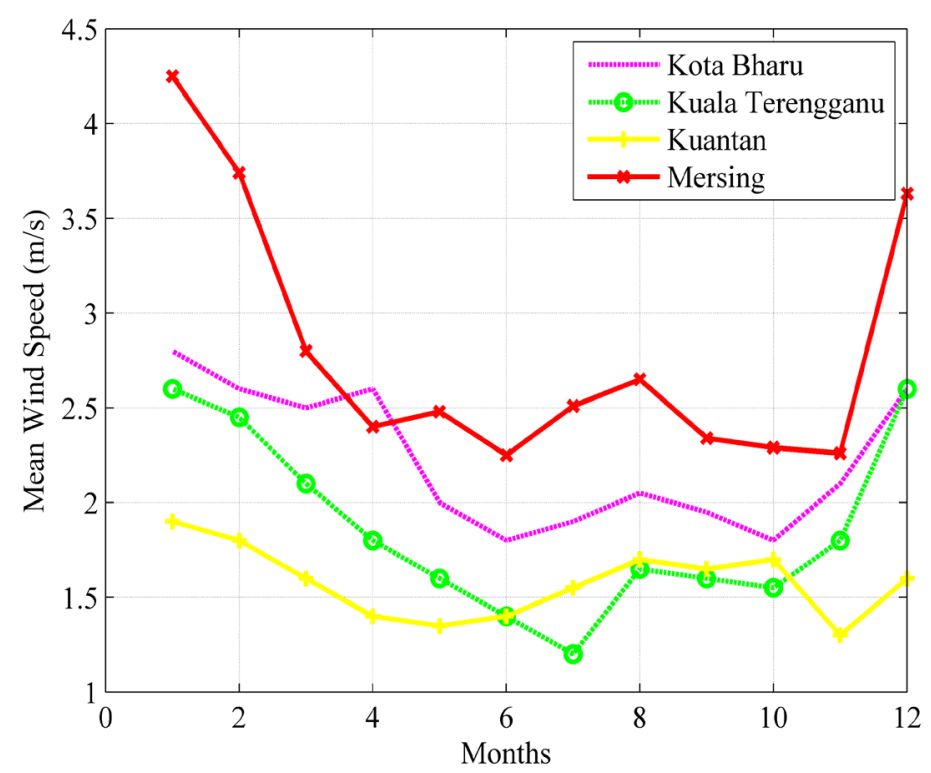

Figure 3. Mean wind speed data from four east coasts of Malaysia weather stations throughout the year 2017.

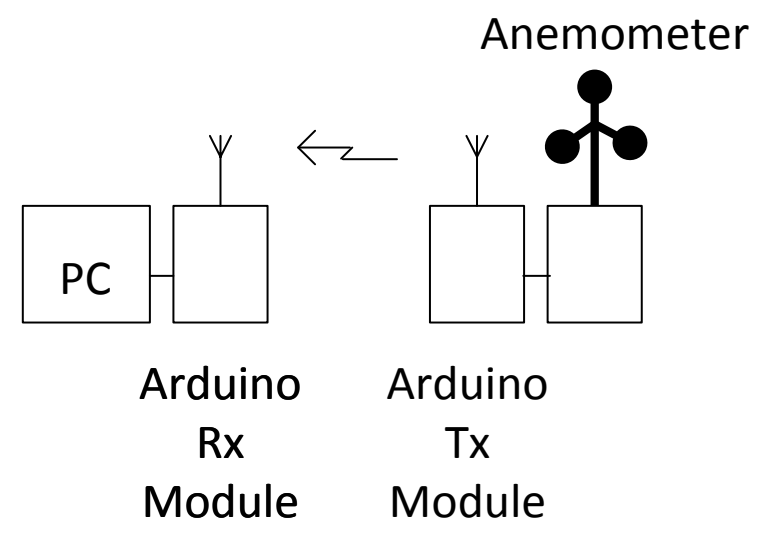

Figure 4. The system setup for the wireless wind speed logging system using Arduino modules.

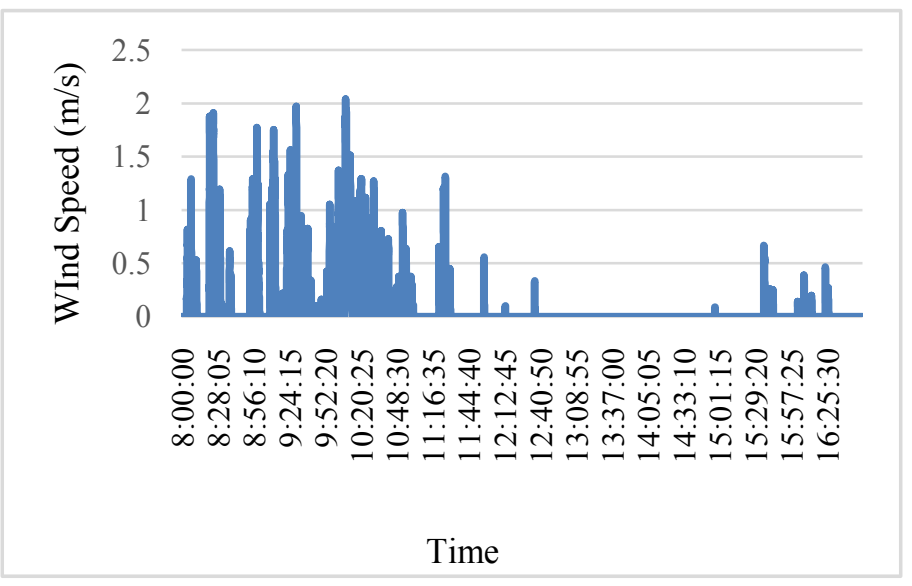

Figure 5. Measured wind speed at the proposed site for 48 hours. 
system is done by a group of researcher from the Faculty of Electrical Engineering, UiTM Terengganu, Dungun Campus. From June 2015 until recent time, the wind speed at the wind turbine generator location is monitored and recorded. Figure 6 depicted the recorded wind speed data. As highlighted in the figure, a comparison is made between the wind speed data recorded at the proposed site to the others published data. The recorded data is not much different from others, except the mean average speed is the highest.

As labelled in Figure 5, the load for the energy generating system is the batteries. The alternating voltage measured at the output of the energy generator and the DC voltage across the batteries are recorded for every second. The measured data is recorded wirelessly through the Arduino Tx-Rx module. The power generated from the wind generator is calculated and the sum of power for every month starting from June 2017 to December 2017 is reported in Figure 7. The highest output power is obtained in November 2017.

The accumulated energy stored in the storage devices is also recorded and reported in the same figure. The lowest energy stored is happened in September 2017, and the highest is in November 2017.

In Malaysia, the tariff for renewable energy starting rate is typically fixed at RM1.20 per kilowatt hour. At this rate, the income expected can be generated depicted in Figure 8. Figure 9 illustrated the estimated amount of energy and power could be generated by the wind turbine.

As illustrated in Figure 10, the amount of system efficiency when directly converted to capital revenue throughout the month is been reported. The minimum revenue is RM500 on September, and RM4000 on November. The minimum revenue reflected the lowest system efficiency which is closed to $3 \%$. The maximum revenue is obtained as the system efficiency reached to $10 \%$. There will require some reduction in the electricity bill if the amount is subtracted from the campus electricity bill. However, the amount is too small and does not affect the bill significantly. Thus, there are few recommendations needed to be done to improve the system efficiency. Firstly, the location of the proposed

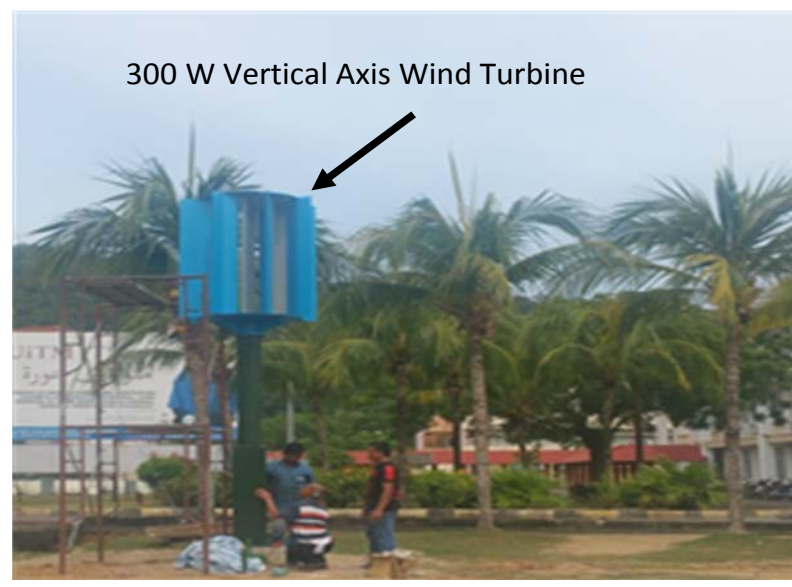

Figure 6. The $300 \mathrm{~W}$ vertical axis wind turbine generator. 


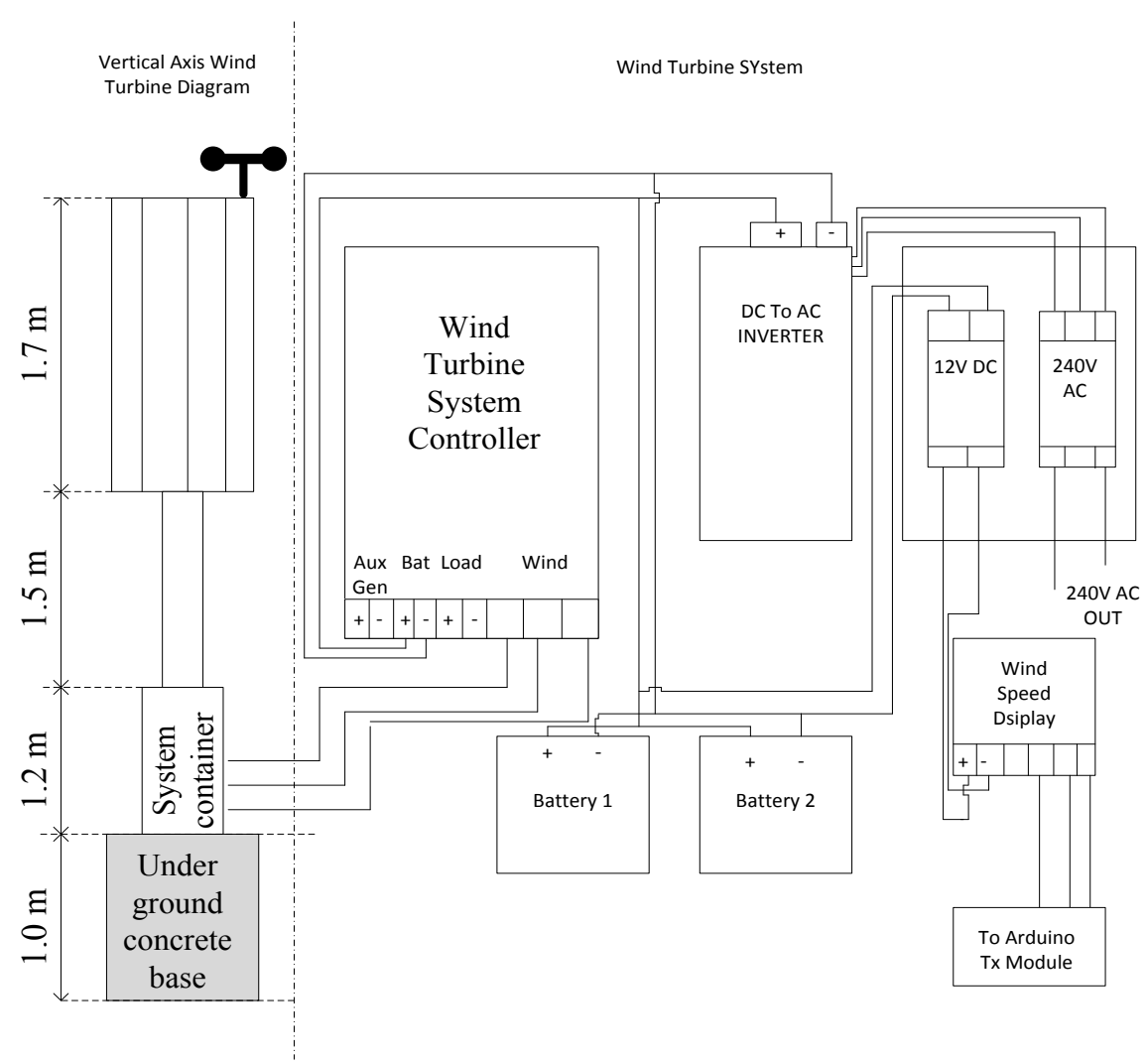

Figure 7. The vertical axis wind turbine generator schematic arrangement.

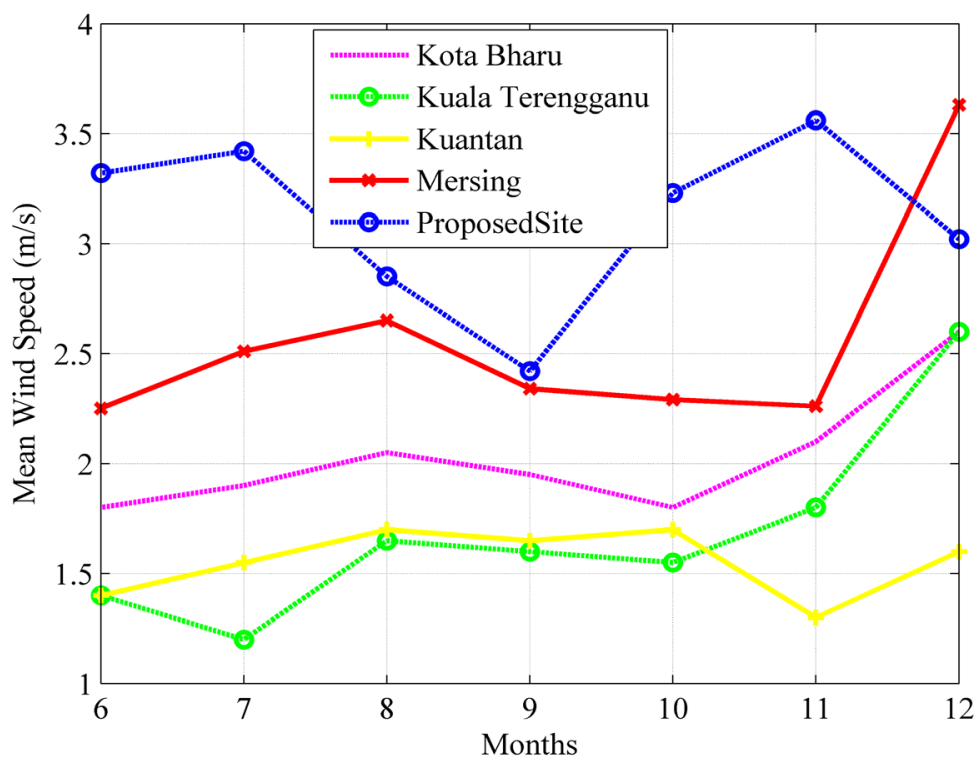

Figure 8. Wind speed data comparison between the proposed site and other published data.

vertical axis wind turbine needs to relocate close to the seashore without any obstruction from the existing building or tree. Secondly, the wind turbine needs to be reconfigured to starts generating energy for a wind speed of $1 \mathrm{~m} / \mathrm{s}$, and when the wind speed is close to $3 \mathrm{~m} / \mathrm{s}$, the efficiency of the system should be close to $80 \%$. 


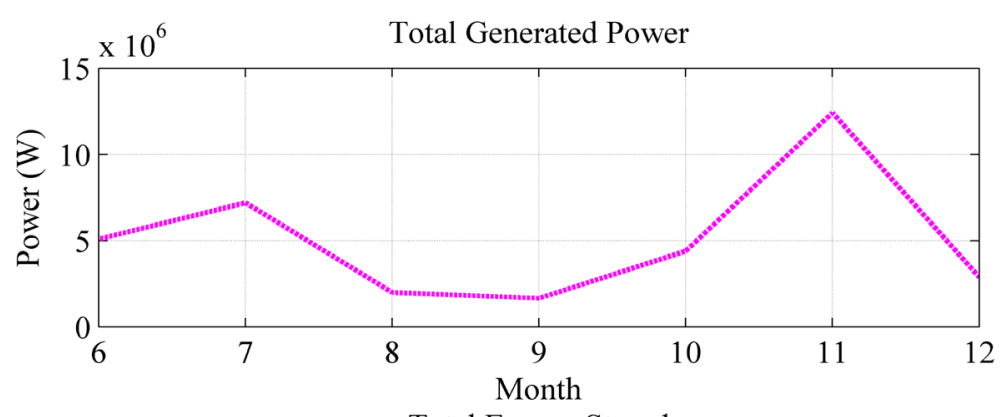

Total Energy Stored

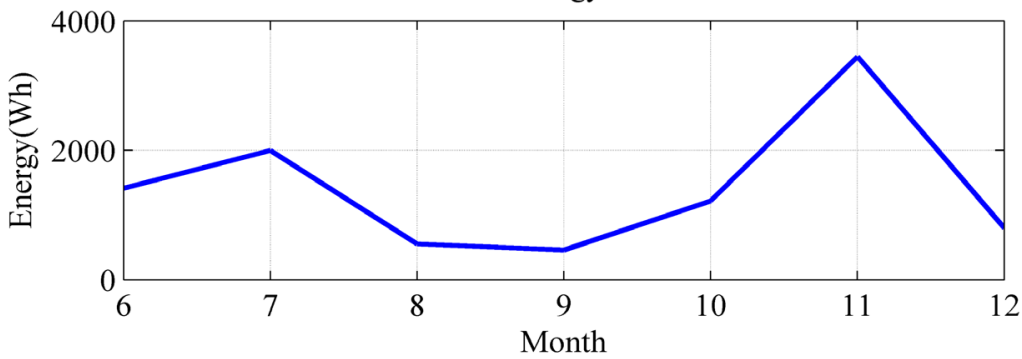

Figure 9. The estimated total generated power and energy harvested from the proposed vertical axis wind turbine.

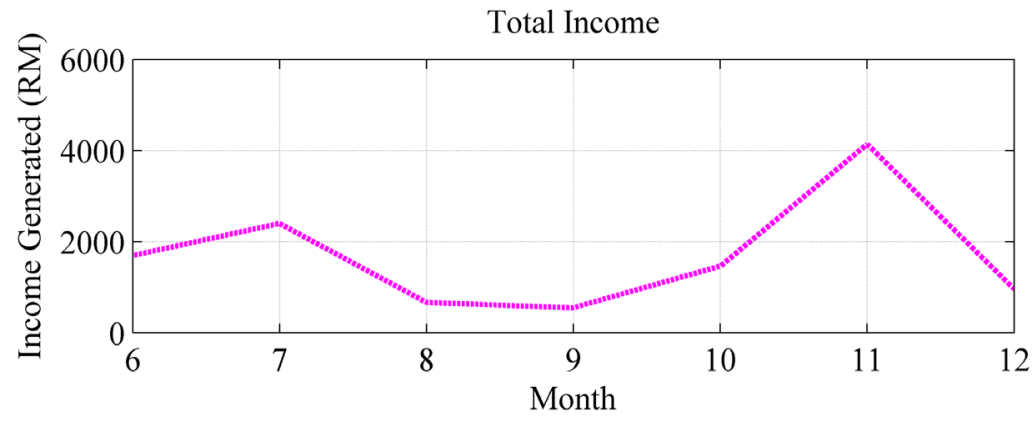

System Efficiency

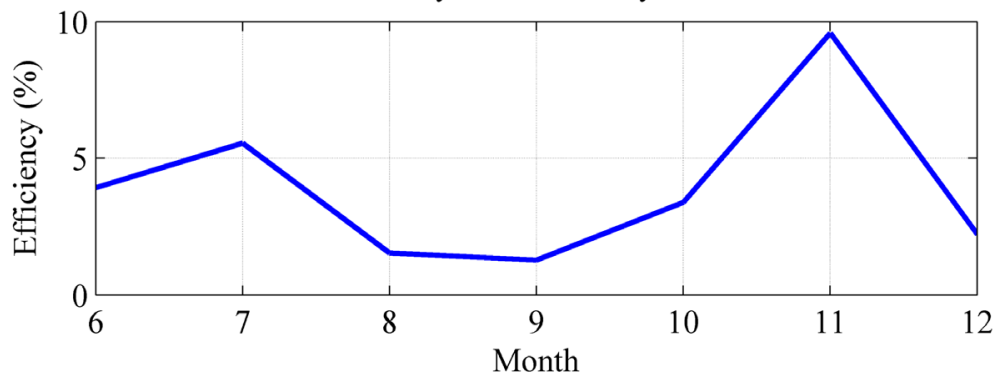

Figure 10. The expected revenue generated and the system efficiency of the vertical axis wind turbine generator.

\section{Conclusion}

In this paper, a preliminary study on generating free electrical energy in UiTM Terengganu harvested from the wind is reported. Previous research and published data are used in designing the suitable wind turbine at the proposed site. By referring to the published and measured wind speed, an appropriate wind turbine which is a vertical axis wind turbine is designed and installed at the 
proposed site. For about six months' actual data on wind speed, output power and energy stored in a storage device has been recorded and reported. It has been found that, averagely, the wind speed at the proposed site is in between 2.0 to $3.7 \mathrm{~m} / \mathrm{s}$. From the calculation, the efficiency of the energy generation system is less than $10 \%$, contributing to an income produce approximately RM4000 per month. The main objective of the wind turbine is to reduce the campus utility bill, in particular, the electricity bill. However, the amount generated does not affect the electricity bill significantly. Further, optimisation or reconfiguration on the suitable location of the wind turbine and power generation system can improve the proposed wind turbine efficiency and the reduction on the electricity bill can be achieved. Further consideration should be taken for the next study where much simpler and smaller vertical wind turbine generator will make the system installation easier. Internet of Thing device also needs to be integrated with the system. The integration will make the proposed system more user friendly and match with the current technology.

\section{Acknowledgements}

This work is supported and funded by Steelcon Energy Sdn Bhd in collaboration with the Faculty of Electrical Engineering, UiTM Terengganu.

\section{Conflicts of Interest}

The authors declare no conflicts of interest regarding the publication of this paper.

\section{References}

[1] Darus, Z.M., Hashim, N.A., Manan, S.A., Rahman, M.A.A., Maulud, K.A. and Karim, O.A. (2009) The Development of Hybrid Integrated Renewable Energy System (Wind and Solar) for Sustainable Living at Perhentian Island, Malaysia. European Journal of Social Sciences, 9, 557-563.

[2] Zaharim, A., Najid, S.K., Razali, A.M. and Sopian, K. (2009) Wind Speed Analysis in the East Coast of Malaysia. European Journal of Scientific Research, 32, 208-215.

[3] Chiang, E.P., Zainal, Z.A., Aswatha Narayana, P.A. and Seetharamu, K.N. (2006) The Potential of Wave and Offshore Wind Energy in around the Coastline of Malaysia that Face the South China Sea. Proceedings of the International Symposium on Renewable Energy: Environment Protection and Energy Solution, Malaysia, 762.

[4] Daut, I., Irwanto, M., Suwarno, S., Irwan, Y., Gomesh, N. and Ahmad, N. (2013) Potential of Wind Speed for Wind Power Generation in Perlis, Northern Malaysia. TELKOMNIKA (Telecommunication Computing Electronics and Control), 9 575-582. https://doi.org/10.12928/telkomnika.v9i3.750

[5] Sopian, K., Othman, M.Y.H. and Wirsat, A. (1995) The Wind Energy Potential of Malaysia. Renewable Energy, 6, 1005-1016. https://doi.org/10.1016/0960-1481(95)00004-8

[6] Oh, T.H., Pang, S.Y. and Chua, S.C. (2010) Energy Policy and Alternative Energy in Malaysia: Issues and Challenges for Sustainable Growth. Renewable and Sustainable Energy Reviews, 14, 1241-1252. https://doi.org/10.1016/j.rser.2009.12.003 
[7] Tiang, T.L. and Ishak, D. (2012) Technical Review of Wind Energy Potential as Small-Scale Power Generation Sources in Penang Island Malaysia. Renewable and Sustainable Energy Reviews, 16, 3034-3042.

https://doi.org/10.1016/j.rser.2012.02.032

[8] Agarwal, T., Verma, S. and Gaurh, A. (2016) Issues and Challenges of Wind Energy. International Conference on Electrical, Electronics, and Optimization Techniques (ICEEOT), Chennai, 3-5 March 2016, 67-72.

https://doi.org/10.1109/ICEEOT.2016.7754761 